\title{
Plasticity and the ageing mind: an exemplar of the bio-cultural orchestration of brain and behaviour
}

\author{
PAUL B. BALTES and TANIA SINGER
}

Max Planck Institute for Human Development Lentzeallee 94, D-14195 Berlin, Germany. Fax: 49-30-8249939; E-mail:sekbaltes@mpib-berlin.mpg.de

Genetic interventions will improve the genome, but they will never make a human being out of the human animal

Using research on the ageing mind, support is offered for the concept of bio-cultural sciences. The bio-cultural sciences highlight the notion that human behaviour is the joint and co-constructive expression of biological-genetic and cultural-societal processes and conditions. The genome determines the ontogeny of the brain; however, so does the cultural-social environment and individual behaviour. The study of the ageing mind illustrates this principle of bio-cultural co-construction. One fertile theory distinguishes between the declining biology-driven cognitive mechanics and the maintained or even increasing culture-driven cognitive pragmatics. Beginning in early adulthood, the plasticity of the cognitive mechanics decreases with advancing age, but the cognitive pragmatics exploit the opportunities of culture and the experiential and interpersonal contexts in which people develop and, therefore, they can exhibit lifelong positive expressions. Professional expertise, artistic competence, social-emotional intelligence and wisdom are examples of late-life potentials in the cognitive pragmatics. This view does not exclude the fact that, in the oldest (Fourth Age), ageing losses become more prominent and affect the cognitive pragmatics as well. A general developmental theory is presented that illustrates how, within the limits offered by biological- and culture-based plasticity, successful ageing is accomplished by the orchestration of three behavioural processes: selection, optimization, and compensation.

\section{Introduction}

The field of human gerontology has changed, and this change can be used to illustrate another, more general, sea change in the life sciences, the emergence of what we call the bio-cultural 
sciences. From a field that conceptualized human ageing as a universal decline in functioning, the new view is to think about human ageing as a combination of gains and losses in function, although with an age-related shift toward a less positive balance sheet of gains and losses. ${ }^{5,68}$ Such a differentiated and multidirectional view of human ageing was always part of the cultural sciences. For humanists, social, and behavioural scientists, expressions of human ageing always contained some signs of positivity and reasons for celebration. ${ }^{32,69,47}$ Among the putative positive aspects of old age were deeper insights into the existential questions of life associated with the human condition, as illustrated by such topics as wisdom and spirituality. Now, the biological sciences have joined in this new multidirectional gain-loss vista of the nature of human ageing.

In other words, whereas a couple of decades ago the field of gerontology and, in particular, its biological sector was busy counting the wrinkles and losses of ageing, there is growing excitement about the 'new' and 'happy' gerontology. ${ }^{57}$ Across a wide range of disciplines, scientists are arguing that theories and methods are available - or in the making - that have the potential to generate a better state of old age. This is true, even though there is another recent and less optimistic story about the oldest-old. This less optimistic story suggests that this excitement of the new gerontology is primarily applicable to what, nowadays, is often called young old age or the 'Third Age'; that is, the age range up to 80 years or so. For the 'Fourth Age', the age range beyond 80, the future of old age is less positive. 2, 6, 11, 64

The topic of the ageing mind is an excellent illustration of the potential and limits of the good and bad news of the new gerontology. This is so because, in the description and explanation of the growing and ageing mind, biological, psychological, and social-cultural factors meet. Neither is sufficient to understand the complexities of the ageing mind. Biological, psychological and cultural factors act together and not always in harmony, in orchestrating how intelligence and other facets of the mind develop and age.

The new view of the ageing mind is closely linked to a perspective that can be characterized as bio-cultural co-constructivism. To illustrate the innovative power of this orientation we begin with a characterization of its opposites. Because the excitement about recent work on the human genome and its promise for understanding the mind is so much in the foreground of everyday discourse, we want to make sure that the joint and co-constructive role of biology and culture for the growing and ageing of the mind are not lost in the current-day spirit of geneticism.

Modern work on the genetics of the brain is easily misconstrued as evidence for biological determinism, for the superior power of biological genetic over environmental-experiential factors. Actually, two forms of determinism are operative: genetic determinism and brain determinism. With genetic determinism, we mean the direct control of intelligence through genes and their expression. With brain determinism, we mean the view that human behaviour is regulated by brain-based influences.

Such genetic determinism and brain determinism biases, if they exist - and this seems occasionally true, especially for media coverage - need correction. Of course, human geneticists are correct when they argue that the mind is constrained by what the biological-genetic foundation of the brain permits. Brain scientists are also correct in stating that cognitive behaviour is represented in the brain. Behavioural and social scientists, however, are also correct when they, in turn, argue that the same is true for the constraining and enhancing 
role of culture-based factors on the brain. In this line of thought, genetic interventions, for instance, will improve the genome and its brain-related expressions, but they will never make a human being out of the human animal.

\section{On the bio-cultural orchestration of the brain}

To prevent a possible misunderstanding, let us emphasize that a genetic and brain determinism bias is not accepted by all researchers in the field of the genetics and the brain sciences. On the contrary, aside from psychologists, many neuroscientists have systematically invested their efforts to show how aspects of culture, such as environmental and learning conditions, shape the structure and function of the brain-behaviour system in reciprocal, continuing, and historically increasing ways. ${ }^{16,20,68,22,65,63}$ Brain plasticity and behavioural plasticity are the lead concepts that signal such work.

Indeed, during the last decades, major strides were made in rejecting simple models of biological or cultural determinism. ${ }^{24,70}$ There is general agreement that the mind is the bio-cultural co-construction of two interactive systems of influences: internal geneticbiological and external material-social-cultural. ${ }^{15,35,40}$ The brain is the joint outcome of these two systems of inheritance. The genome and the environment, including culture, are equal partners in laying the foundation and the subsequent organization of the mind. From a long-term historical perspective, the relative role of cultural factors has increased. This is due to the fact that time scales for genetic and cultural transmission differ. For instance, in modern times, the genome has remained relatively stable, but the production of culture and its spread, including that between generations, has increased dramatically. In our view, this supports the conclusion that the more recent 'emerging' properties of mind are primarily associated with cultural factors. There should be no misunderstanding, in the spirit of bio-cultural co-constructionism: this does not deny that biological brain potential is a necessary precondition for the emergence of culture itself.

The concept of bio-cultural co-construction used in this new view of the brain-behaviourculture interface implies that, throughout evolutionary history, the genetic and the cultural conditioned and influenced each other in major and cumulative ways. This is also true for individual development from birth into old age. In this approach, the brain is seen as a dependent variable. Its basic foundation includes the expression of the environment and the culture into which brains are born as well as the activity of individuals as they live their lives. Since the scope and depth of culture are more recent events, the relative power of cultural factors on the brain has accelerated.

To illustrate: first of all, the biochemical and biophysical architecture of the brain itself carries the stamp of culture and lifelong experiences. For example, people who are practised string players, have in their brains a larger somatosensory representation of the digits of their left hand in comparison with fingers of their right hands or with the fingers of the left hands compared with people who do not play an instrument. ${ }^{26}$ Similarly, blind individuals who read Braille have increased cortical representations of their Braille-reading finger pads compared with either sighted or non-Braille-reading controls. Interestingly, it has also been shown that representations of parts of the hand that were not employed in Braille reading were, in contrast, 
differentially smaller than in control hands. ${ }^{53}$ Thus, performance at one task will change the cortical representations in favour of that task at the expense of some unpractised task. ${ }^{20,25,55}$

These examples can be extended by numerous thought experiments: for instance, the question to what degree learning a single language first or learning several languages at once alters the organization of the brain. As soon as one opens one's mind to such thought experiments, they illustrate that, throughout life, the cerebral cortex is continuously modifying its topological and functional properties in dependence on environmental-cultural changes and life experiences. Moreover, such results on the impact of culture-based experience on brain structures and functions also account for broad inter-individual differences found in behavioural expressions of human beings, such as intelligence.

Secondly, note that the developed brain is in constant need of the environment, to be stimulated and to be guided in its activities. Like the regulating influences of the genome, this input and feedback by cultural products (such as libraries and the media) and cultural agents such as social partners, is not random. It is selective and structured in the same way that the gene-based brain is selective and structured. Thus, societies and cultures are more than what is stored in and expressed through individual brains, ${ }^{13}$ and the resulting brain outcomes in modern societies can be different from the architectural patterns that 'genetically identical' brains exhibited at earlier evolutionary times. Furthermore, the social and cultural sciences teach us that collective and interactive-mind conditions and paradigms are the foundation of the culture-based mind. Here, the neurosciences with their current focus on individual brains have a long way to go to represent what culture as a collective, interactive-mind enterprise is all about.

\section{The interplay between brain plasticity and cultural plasticity}

The concepts of brain and behavioural plasticity are particularly good examples to illustrate the kind of productive interdisciplinarity and reciprocal causation that exists in the bio-cultural constitution of the brain. In general, brain plasticity refers to the capacity of the brain to change cortical representations as a function of experience. The concept of behavioural plasticity denotes the same on the behavioural level. ${ }^{12,43,62}$

Stretching the analogy, one can speculate that there is an environmental-cultural equivalent to brain and behavioural plasticity. This equivalent could be called cultural plasticity. Cultures differ in the level of resources (opportunities) they offer for individual development, in profiles of behavioural expressions, in the constellations of interactive minds, as well as in their receptivity to modification by behaviour of individuals and new technological conditions. If one lives in a culture with a restricted range of variability and opportunities for learning, the brain remains less developed.

A further thought experiment might help to explore the boundary conditions of the brain-culture-plasticity interface. Are there environment-based and culture-produced influences that could change the brain in fundamental and even qualitatively different ways? One example would be a case where elements that are not part of the brain, such as specific anti-oxygens, are imported into the brain through nourishment. In principle, this import could, in interaction with what is available in the brain, produce a new state of biochemical or 
biophysical functioning. Similar thought experiments could be conducted in the context of future developments of modern medical-biological technologies, such as where specific microchips or electrodes are implanted into the brain resulting into new neuronal structures and functions.

\section{Lifespan psychology}

One line of inquiry that has exemplified the notion that biology and culture interact in the production of the structure and function of the brain and behaviour is 'lifespan psychology' and, within that field, particularly research on the structure and function of intelligence and related cognitive capacities across the lifespan. ${ }^{5,10,15,36,52}$ By looking at the entire lifespan, the joint orchestration of human development through societal-institutional, psychological, and biological factors becomes evident.

Four lines of work by lifespan psychologists are of particular importance: (1) the first is a theoretical frame to help us understand the overall architecture of the life course; (2) the second is a theory of intelligence that distinguishes between two categories of intellectual functioning, the biology-based cognitive mechanics and the cultural- and knowledge-based cognitive pragmatics; (3) the third is work on cognitive plasticity and its development across the lifespan; (4) the fourth is research on how people, as they age, succeed in maintaining high levels of cognitive functioning and move forward in selected domains of new development.

\section{Biological and cultural frames of lifespan development}

Drawing on both evolutionary and ontogenetic perspectives, ${ }^{5,6}$ the lifespan dynamics between biology and culture can be characterized by three major principles (see Figure 1). First,

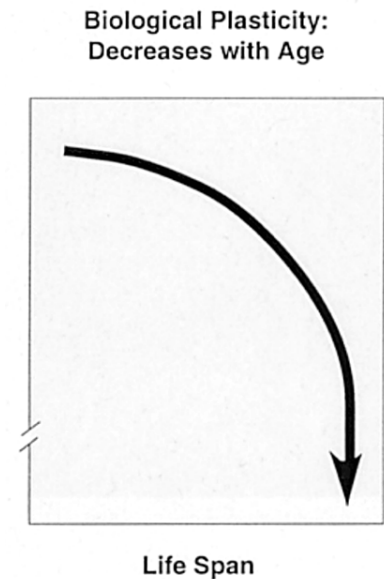

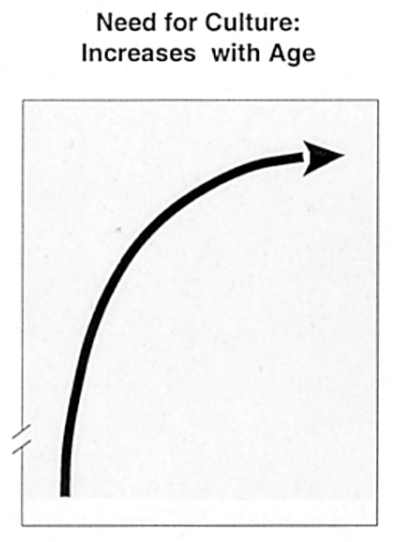

Life Span

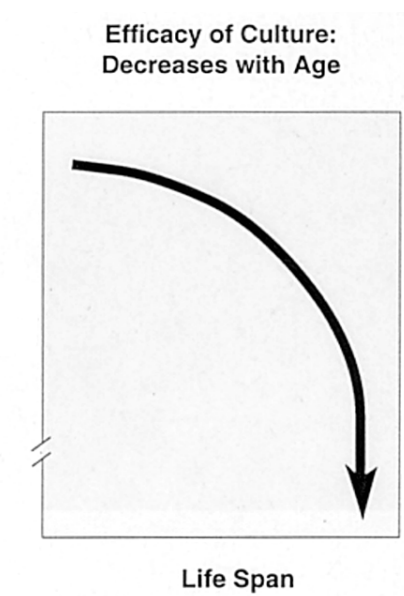

Life Span

Figure 1. Schematic representation of three principles governing the dynamics between biology and culture across the lifespan. There can be a lot of debate about the specific forms of the functions, but less about directionality. 
evolutionary selection pressure displays a negative age correlation, ${ }^{28,51}$ and therefore genome-based plasticity and biological potential decrease with age. Secondly, for growth aspects of human development to cover more and more of the biologically possible maximum lifespan, culture-based resources are necessary and required at ever-increasing levels. Thirdly, because of age-related losses in biological potential, the efficiency of culture is reduced as the lifespan development unfolds and old age is reached.

From an evolutionary perspective, the notion of a negative age correlation of selection benefits results from the fact that the selection-driving process of reproductive fitness is located in young adulthood. As a consequence, evolutionary selection operated primarily during the first half of life. ${ }^{29,51}$ Accordingly, genetic expressions at later stages are more often deleterious or dysfunctional than those operative at earlier times in the lifespan. In short: 'Evolutionary biology was not a good friend of age'.

The argument for an age-related increase in the need for culture has two main parts. First, for human development to have reached higher and higher levels of functioning there had to be a conjoint evolutionary increase in the richness and dissemination of culture and its opportunities. Culture, for instance, was the primary motor for the sharp increase in longevity during the 20th century, not changes in the genome. Secondly, because ageing is associated with a decrease in the biological efficiency of the organism to maintain functions, this loss requires an increase in the supportive and compensatory role of culture-based resources.

The third cornerstone is that, with ageing, cultural factors - such as learning and imitation - become less effective. This is primarily, but not only, due to the age-related loss in biological potential and its negative consequences on learning potential. There are also the limitations on new learning that stem from the learning process itself. We should consider lifespan development in analogy to learning curves. Learning curves are often exponential. In later phases, as individuals reach asymptotes, further progress becomes smaller and smaller. Another disadvantage of high levels of learning and associated specialization is negative transfer from one domain to another.

\section{A dual-process theory of lifespan intelligence}

Consistent with this general view of the biological and cultural architecture of the life course is a theory of intelligence or cognitive resources (see Figure 2) that distinguishes between two major categories of intellectual functioning: the biology-based cognitive mechanics and the culture-based cognitive pragmatics. ${ }^{5,15,46}$ A forerunner of this theory were considerations by Donald Hebb (1949) and the model of fluid and crystallized intelligence proposed by Cattell (1971) and Horn (1982).

The cognitive mechanics are the cognitive primitives generated by biological-genetic evolution and they represent the basic information processing, learning, and memorizing that humans are capable of. They are indexed by the speed, accuracy, and coordination of elementary operations of information processing and their use in generating memory. In everyday words, one could speak of the mechanics as the physiologically pre-programmed hardware of the brain. As is true for other bodily (physical) aspects of lifespan development, the predominant pattern of lifespan change in the cognitive mechanics is growth (maturation) 


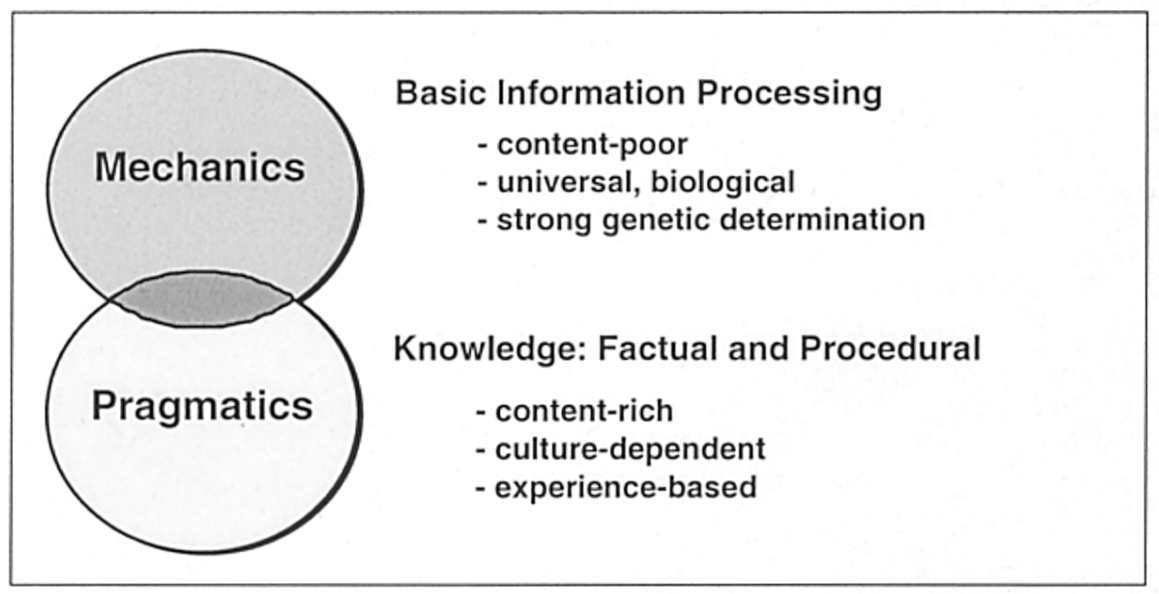

Figure 2. The dual-process model of lifespan intellectual development. Two distinct components of intelligence, the cognitive mechanics and the cognitive pragmatics.

in childhood and adolescence, followed by stability in early adulthood, and ageing-induced decline. This decline begins as early as middle adulthood.

In contrast to the mechanics, the cognitive pragmatics of intelligence are fundamentally associated with the role of culture and cultural determinants. Their primary substrate is culture-based knowledge and cultural learning. One could speak of the cognitive pragmatics as the culture-based software of the brain. Being able to speak a language, being able to read and write, solving formal-logical thinking problems, acquiring a specific professional expertise, being able to write a poem or compose a piece of music, having an identity concept of oneself, are prototypical examples of the cognitive pragmatics.

Because the cognitive pragmatics reflect the acquisition and lifelong practice of culturally transmitted bodies of declarative and procedural knowledge, developmental changes in the cognitive pragmatics and their associated brain transformations extend farther into the lifespan. It is in the cognitive pragmatics where culture reigns, and where individuals, for instance through intensive effort, imitation, deliberate practice, and cultural innovations, can develop into knowledgeable human beings.

Due to individual, group, and cultural variations in context, as well as idiosyncratic life experiences, the lifespan script of the cognitive pragmatics has multiple aspects and exhibits both commonalities and sizeable differences in trajectories between individuals and content-domains. Some pieces of the cognitive pragmatics are fairly general, such as the ability to speak a particular language. Other parts, however, such as specific expertise-related skills - for example, playing chess or composing music - are more person-specific if not idiosyncratic. As we move through life, and depending on cultural conditions, we select, engage, and disengage from activities. Thus, a complex pattern of gains and losses in the cognitive pragmatics can result. ${ }^{15,23,52}$ In this vein and on the level of brain functioning, the cognitive pragmatics contribute a major share to what occasionally is called the 'personalized' brain. 

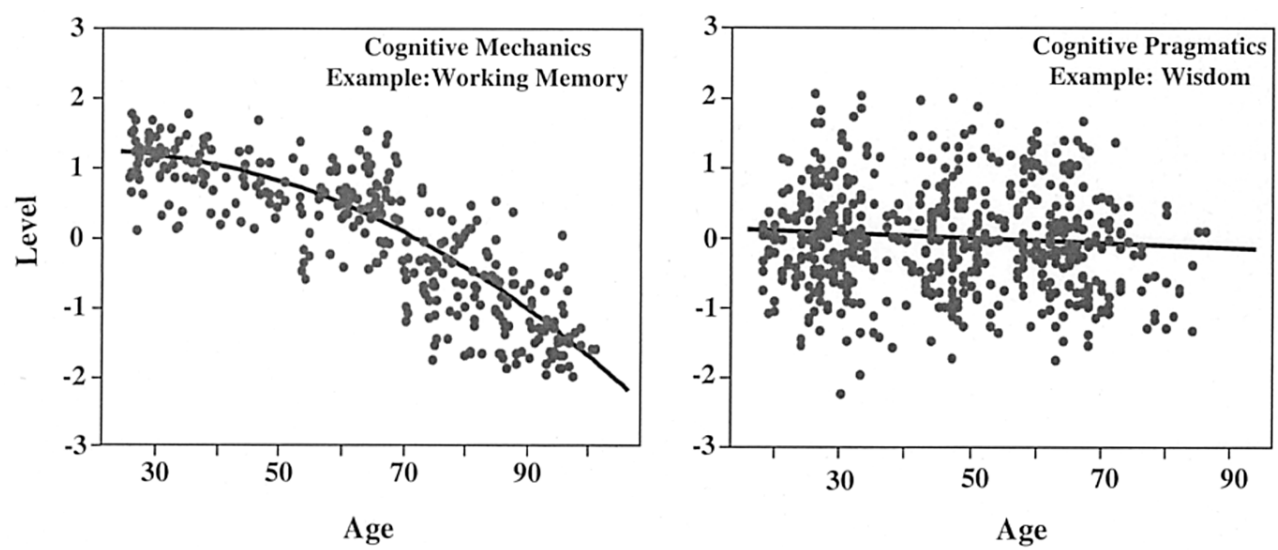

Figure 3. Adult age gradients for prototypical measures of the cognitive mechanics and the cognitive pragmatics. ${ }^{48,67}$

The mechanics and the pragmatics are not independent of each other. In everyday life, most intellectual tasks involve both; they form an interactive and collaborative system. For example, by using pragmatic techniques, such as the memory technique of the method of loci, one can recall hundreds of words in the correct order, although the cognitive mechanics by themselves would permit the recall of no more than something like 5-7 words. However, there are also conditions where the cognitive mechanics are interfering with what the cognitive pragmatics aspire to. This may be true, for instance, when the evolutionarily earlier contexts with their resulting changes in the cognitive mechanics do not square with the adaptive challenges of the modern world. And finally, in old age, the cognitive mechanics may fall below the limit required for the cognitive pragmatics to function well.

Empirical data support the prediction of the dual-process theory of intelligence, namely that cognitive mechanics and cognitive pragmatics follow differential lifespan trajectories (see Figure 3). The results of studies using psychometric cognitive measures show that the biology-driven cognitive mechanics, reflected in measures of reasoning, speed, episodic and working memory, show a general growth pattern up to early adulthood. Fairly early, however, because of their close ties to biology and genome-based determinants, the speed and accuracy of basic information processing show systematic and continuous losses in functioning. The left-hand panel of Figure 3 illustrates this general declining pattern of the cognitive mechanics for a prototypical mechanic ability, the working memory. In contrast, the cultural-based pragmatics, usually represented by the abilities of knowledge and language, display later onsets of decline ${ }^{48,58}$ Because tasks involved in the measures of the cognitive pragmatics are usually heavily confronted with components of the mechanics, data obtained with commonly used psychometric measures probably represent an underestimation of the pragmatic potential.

Research on cognitive pragmatics needs innovative efforts and new models of measurement. One domain that has recently received much attention as an exemplar of a more salient form of the cognitive pragmatics is the topic of wisdom. ${ }^{14}$ Psychologists define wisdom as an expert 
system in the knowledge and skills of the conditions and conduct of life. Related constructs are social and emotional intelligence.

Using answers to difficult life dilemmas, which require wisdom-type knowledge, psychologists demonstrated that the emergence of wisdom occurs later in ontogeny than is the case for tasks of the biologically driven cognitive mechanics. ${ }^{14}$ The peak period of development for the cognitive mechanics is childhood and early adolescence. Contrariwise, regarding cognitive pragmatics, it is in young adulthood (the 20s and 30s) where this culture-based knowledge systems shows its major advances. ${ }^{54}$ Moreover, (the right-hand panel of Figure 3), older adults perform well on wisdom tasks, at least up to age 75 . Similarly, older adults are very effective when it comes to situations demanding social and emotional intelligence. ${ }^{18,42}$

However, even aside from such topics as wisdom and emotional intelligence, similar positive outcomes were obtained in areas closer to everyday functioning. In the domains they select for continued optimization and further development of their cognitive pragmatics, older adults, on average, demonstrate sizeable cognitive plasticity and high levels of efficacy, and this is despite their age-associated losses in the speed of information processing. ${ }^{56}$ Older expert pianists, for instance, showed nearly no age-related decline on music-related tasks, although they displayed the normal pattern of large age-related reductions in standard measures of general processing speed. ${ }^{41}$ Apart from professional expertise, ${ }^{21,27}$ similar age-friendly results have been found in the arts, including painting, composing, and writing. ${ }^{59,60}$

Because of its close dependence on the biological conditions of ageing, in old age the brain becomes a major constraining force to what is possible. With ageing, the level of cognitive mechanics moves continuously downward and, if individuals live long enough, their level is likely to drop below a functional threshold. Normal ageing and pathological ageing contribute jointly to this downward trajectory of the cognitive mechanics. As a consequence, the cognitive mechanics in late life offer a smaller and smaller pool of information processing resources that can be used for the nurturing and acquisition of culture-based knowledge; that is, the maintenance and the further refinement of the cognitive pragmatics.

As a result of this general loss in cognitive mechanics, in very old age all categories of intellectual functioning exhibit a pattern of decline. ${ }^{11,48}$ Empirical observations from the Berlin Ageing Study could show that differences in directionality between mechanical and pragmatic abilities tend to disappear in the Fourth Age. The cognitive mechanics become more powerful in the regulation of the mind. Furthermore, in old age, biological factors become more prominent, even in determining individual differences in the knowledge-based cognitive pragmatics. $^{48}$

\section{Cognitive plasticity: lifespan changes}

As mentioned already, two centrepieces of cognitive neuroscience and psychological research are brain and behavioural plasticity. Research on behavioural plasticity brings most clearly into focus the issue of the dynamics between brain and cultural potential as well as age-related changes in potential.

On the one hand, psychological plasticity research has generated much optimism about the ageing mind. One piece of the new gerontology is that cognitive plasticity is a lifelong phenomenon. Older adults continue to profit from learning, and the extent of the plasticity 


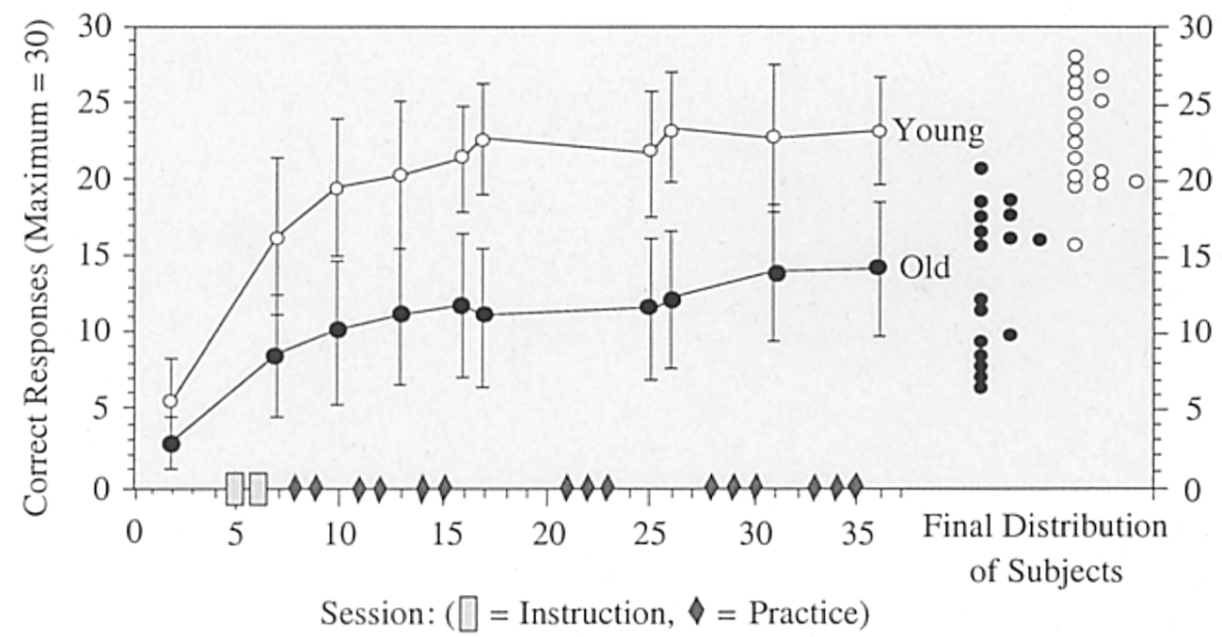

Figure 4. Testing-the-limits research suggests the existence of robust age-related losses in the mechanics of cognition and its consequences on other functions. The example given involves a memory technique, the Method of Loci. After 38 sessions of training, most older adults did not reach the level of performance reached by young adults. In the final distribution, not a single older person was performing above the mean of the young adults (adapted from Ref. 9).

observed is larger than commonly expected. However, and this is in line with the overall landscape outlined (see Figure 1), there is also another side to the lifespan story of behavioural plasticity. Compared with young adults, older adults profit less from performance enhancing training programs. ${ }^{1,3,17,71,72}$ In general, older adults need more cognitive support, more practice and more time to reach equivalent performance improvements.

One form of training that illustrates this ageing-associated loss in cognitive behavioural plasticity most clearly is testing-the-limits work on maximum performance potential. ${ }^{4,37,62} \mathrm{As}$ expected, the results of testing-the-limits training studies, in the domain of episodic memory for instance, display two seemingly contradictory outcomes (see Figure 4). First, older adults continue to have cognitive potential for new learning. Second, however, the more one approaches maximum limits or the peak performance range, the more evident it becomes that the potential for high levels of functioning is much reduced as one approaches old age. In some domains, and despite intensive training and effort, older adults may never be able to reach the same level of functioning as younger adults. $., 38,39$

Recent results of a memory training study conducted with participants in the Fourth Age - that is participants between 75 and 101 years of age - display the most radical evidence for such losses in cognitive plasticity. ${ }^{61}$ Not all participants in this group of the oldest-old are still able to profit from instruction in a mnemonic technique. Moreover, following the basic initiation into the method, most failed to improve their performance. In sharp contrast, young adults continuously improved their memory performance throughout the training. 


\section{Third versus fourth age and the role of dementias in cognitive ageing}

Such marked losses of cognitive plasticity in old age are further magnified when brain pathologies, such as dementias join the normal processes of ageing. ${ }^{3}$ For Alzheimer patients, for instance, even in preclinical stages of the disease, the plasticity potential associated with the cognitive mechanics is reduced to such a degree that new learning becomes nearly impossible. Such findings, and others, ${ }^{2,64}$ have strengthened the suggestion that we need to distinguish between a Third and a Fourth Age. In other words, what we have learned in recent decades about the remarkable continuing plasticity of the mind in the Third Age, may not be generalizable to advanced old age.

Advanced old age, therefore, represents one of the major challenges for new gerontological work. Note in this context that our analyses of the biology-culture dynamics across the life span (see Figure 1) suggests that further advances in the biological and cultural co-construction of functioning in the oldest-old, the Fourth Age, will be more and more difficult to achieve as we are moving into higher and higher ages.

\section{Lifespan script of allocation of resources}

Aside from the question of what intellectual resources consist of and how they vary with age, there is the question of what they are used for. Considering the joint impact of biological and cultural factors on the development from childhood into old age (Figure 1 above), a lifespan scenario results that shows major reorganizations in the level and distribution of the allocation of cognitive resources. In childhood and adolescence, most resources are invested into processes of growth and higher levels of functioning. The further individuals move into adulthood, the more it becomes that cognitive resources are invested into maintenance of functioning and the regulation of losses. With ageing, fewer and fewer of the cognitive mechanics and cognitive pragmatics can be devoted to new learning and the development of new bodies of knowledge.

To understand the implication of this shifting dynamic in the allocation of resources, a general meta-theory of development - selective optimization with compensation (SOC) - has been proposed as a guiding frame. According to this theory, any developmental process can be understood as involving the coordinated orchestration of three processes: selection, optimization, and compensation. ${ }^{7,5,8,50}$ Selection delineates the range of possible alternative options or ends. Optimization involves means to achieve success or desired outcomes. Compensation, finally, comes into play when individuals are confronted with a loss in previously available goal-relevant means and, as a consequence, alternative means have to be acquired and invested to maintain a given level of functioning.

One example that we have used in the past to illustrate this orchestrating processes of selection, optimization, and compensation ${ }^{31}$ comes from an interview with the famed pianist Rubinstein who, at 80 , was asked how he succeeded in remaining such an excellent concert pianist. In his answer, one could find the following. First, that he played fewer pieces (selection). Secondly, that he practised these more often than at earlier times (optimization). And thirdly, that to cover his loss of speed in the motor mechanics of playing, he introduced 
more extreme contrasts in playing speed such as ritardandos (see also Ref. 41 for experimental demonstrations of such compensatory behaviour in ageing pianists).

\section{Intelligence, cognition, and everyday sensor-motor functioning}

The strategy of SOC as a way to manage ageing successfully can be shown in many domains of functioning. ${ }^{31}$ One is motor behaviour and the ageing-associated increases in the cognitive resources that need to be allocated to achieve effective functioning.

The ageing mind is a systemic phenomenon that pervades much of what individuals do. Traditionally, when one speaks about the mind, research highlights the use of intelligence or cognitive resources for the academic-cognitive dimensions of life, for instance for the organization of knowledge, for learning, and for logical problem solving. However, the study of human ageing has pointed out, and this is in line with the shifting profile of allocation of resources mentioned before, that the ageing mind is highly relevant for non-abstract and non-symbolic tasks of everyday life: for instance, how to walk, how to keep one's balance, how to eat, or how to drive a car. At first sight, these activities have little to do with intelligence or cognition.

Research work conducted in our laboratory can be used as an example, both of how cognitive resources are invested into domains other than the classical tests of intelligence, and, in addition, of how we allocated resources through selection, optimization, and compensation; and how in ageing this pattern of allocation changes. ${ }^{49,44}$ To examine this interaction, we designed a laboratory in which, online, walking (speed, accuracy) and memory (recalling lists of words) can be measured. In addition, we arranged for ways to measure compensation when task performance is challenged; for instance, regarding memory by having the option to slow down the presentation of the words to be remembered; or regarding walking, by having access to a handrail on which to lean when walking becomes unstable.

In a study ${ }^{44,49}$ summarized in Figure 5, younger and old adults were asked to memorize and walk at the same time. This dual-task performance, walking and memorizing at the same time, is then compared with the level of performance observed under single-task conditions. The relevant findings are that older adults need more of their pool of cognitive resources to walk than younger adults. Secondly, when deciding to allocate resources, older adults favoured allocation to walking over memorizing. In other words, older adults prioritized walking. Most likely, this is due to the fact that stable motor behaviour in old age has a large survival value. Furthermore, when the task became more difficult, older persons were quite efficient at using compensatory means to maintain walking.

Aside from the significance of these findings for the successful-ageing theory of SOC, such research on sensorimotor functioning exemplifies the fact that the ageing mind is challenged by more than intellectual tasks in the traditional sense. In old age, because the biologically-based mechanics of the body begin to fail, the mind is devoted in ever-increasing ways of managing the fundamentals of the body, such as eating, walking, and keeping one's balance. As a result, less and less cognitive resources are available for nurturing and acquiring those pragmatic bodies of knowledge that are in the centre of culture and our individuality; such as identity, wisdom, and the self. 


\section{Dual-Task Costs $\%$ Loss from Single Task}

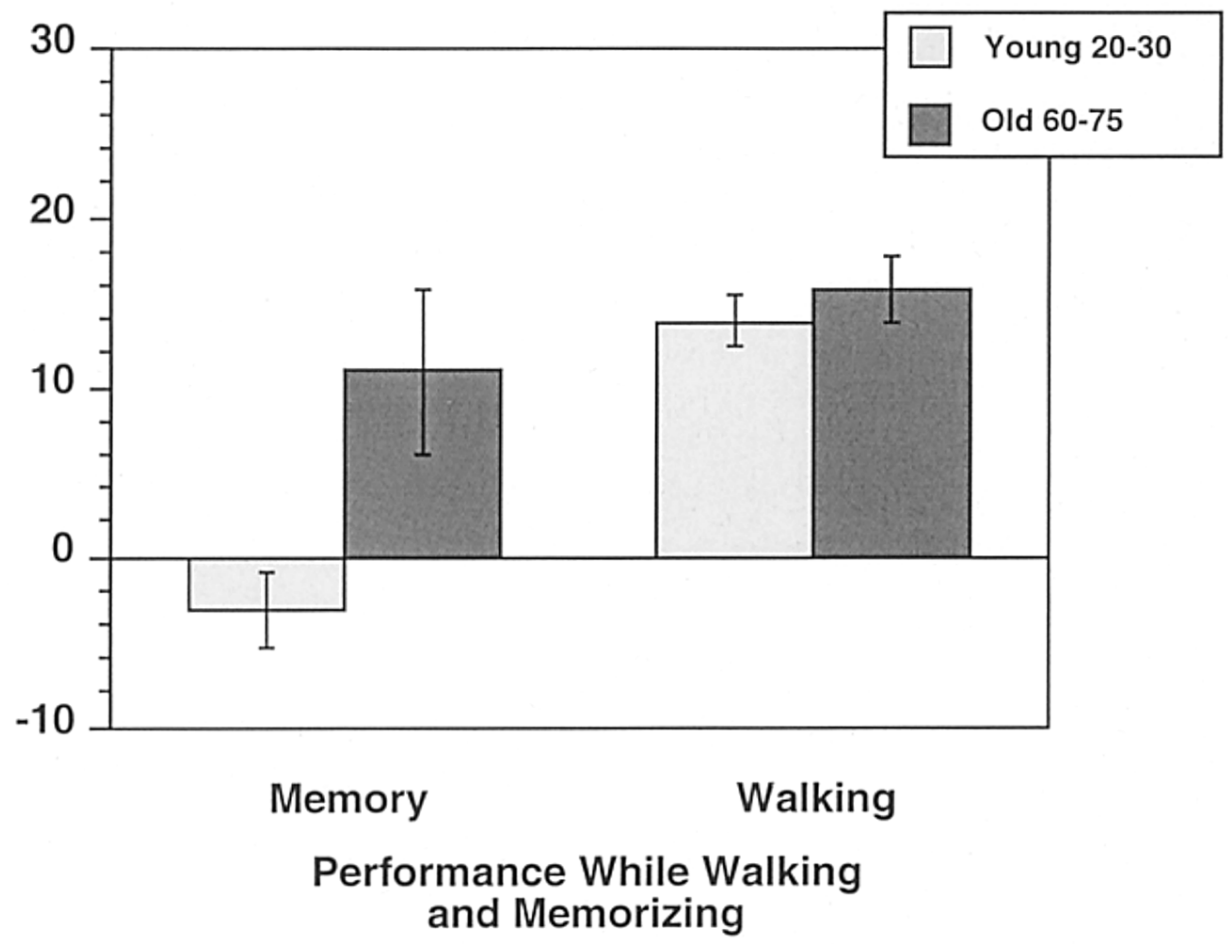

Figure 5. Age differences in dual-task costs: none for walking, but for memorizing. The suggested interpretation is in line with the theory of selective optimization with compensation: older adults prioritize walking over memory (adapted from Ref. 49).

\section{Future perspectives}

Due to the advances of a broad spectrum of disciplines, and societal advances in general, the modern situation of the ageing mind has reached a new level of development, especially regarding the Third Age. In general, the Third Age refers to the age range from about 60 to 80 years. From a century of studying declines of ageing, we have reached a new scenario where cognitive ageing is not just a story of decline, but where we know that the ageing mind entails select opportunities of continued growth. These gains are foremost the reflection of cultural impact.

Successful ageing is inherently a story of selection, optimization and, especially, compensation. Compensating for the biology-induced losses in the cognitive mechanics of the ageing mind seems especially critical. Therefore, aside from the use of training and medical interventions, major advances are to be expected from engineering technology and human-factors psychology aimed at the development of computer-aided instruments, such as external memory notebooks, better hearing aids, and technical visual support systems. Such systems can be expected to permit compensation for some losses in the cognitive mechanics and thereby to free-up resources for the pragmatic and knowledge-based aspects of the mind. ${ }^{30}$ 
The situation is less optimistic as far as the Fourth Age is concerned (the age range from 80 upward). There is no precise definition of when the Fourth Age begins, in part because of shifting life expectancies and historical changes in health. One generalizable and change-sensitive criterion may be to define the onset of the Fourth Age as the chronological age where less than $50 \%$ of the respective birth cohorts survive. For that age range, current medical-technological knowledge and cultural conditions are insufficient to create a state where gains and maintenance of cognitive functioning are a likely outcome.

Thus, especially in light of the increasing number of nonagenarians and centenarians in the population, and associated brain diseases such as dementias, the Fourth Age emerges as one of the major challenges of the 21 st century. For the ageing mind to be optimized in that age range, major efforts in, and coalitions of, intervention genetics, behavioural health programs, biotechnological engineering as well as psychosocial programs are necessary. Note in this context, however, that this recognition of the social challenges of a Fourth Age does not necessarily spell despair. Progress in science is more often than not due to the intellectual and motivational agenda that results from recognizing states of deficit and dysfunction.

Let us return to the opening of this article. In the scenario of the future of the growing and ageing mind, we need to remember that improving the genome through genetic repair and genetic intervention alone, while definitely of major significance especially regarding pathological states and the course of biological ageing, will not be the sole answer. The key conceptual framework is that of bio-cultural orchestration of the brain-behaviour system. Thus, while genetic interventions have the potential to correct for losses in brain plasticity, it is the ensemble of cultural factors and the psychological properties of individuals that co-define, in major ways, the content, the varying outcomes, and the peaks of human experience.

Genetic interventions make us better animals. We become humans, however, because of the ways that culture and our individual constructions exploit the brain and make it our servant. In this sense, and as originally suggested by biologically oriented cultural anthropologists, the 21 st century is the century of the bio-cultural sciences. ${ }^{24}$

\section{References}

1. Bäckman, L., Small, B. J., Wahlin, A. and Larsson, M. (2000) Cognitive functioning in very old age. In F. I. M. Craik and T. A. Salthouse (eds) Handbook of Ageing and Cognition (Mahwah, NJ: Erlbaum) pp. 499-558.

2. Baltes, M. M. (1998) The psychiatry of the oldest-old: The Fourth Age. Current Opinion in Psychology, 11, 411-415.

3. Baltes, M. M. and Baltes, P. B. (1997) Normal versus pathological cognitive functioning in old age: plasticity and testing-the-limits of cognitive/brain reserve capacity. In F. Forette, Y. Christen and F. Boller (eds.) Démences et Longévité (Paris: Fondation Nationale de Gérontologie) pp. 77-101.

4. Baltes, P. B. (1987) Theoretical propositions of life-span developmental psychology: on the dynamics between growth and decline. Developmental Psychology, 23, 611-626.

5. Baltes, P. B. (1997) On the incomplete architecture of human ontogeny: selection, optimisation, and compensation as foundation of developmental theory. American Psychologist, 52, 366-380. 
6. Baltes, P. B. (1999) Alter und Altern als unvollendete Architektur der Humanontogenese. Zeitschrift für Gerontologie und Geriatrie, 32, 433-448.

7. Baltes, P. B. and Baltes, M. M. (1990) Psychological perspectives on successful ageing: the model of selective optimisation with compensation. In P. B. Baltes and M. M. Baltes (eds) Successful Ageing: Perspectives from the Behavioural Sciences (New York: Cambridge University Press) pp. 1-34.

8. Baltes, P. B. and Graf, P. (1996) Psychological aspects of ageing: facts and frontiers. In D. Magnusson (Ed.) The Life-span Development of Individuals: Behavioural, Neurobiological and Psychosocial Perspectives (Cambridge, UK: Cambridge University Press) pp. 427-459.

9. Baltes, P. B. and Kliegl, R. (1992) Further testing of limits of cognitive plasticity: negative age differences in a mnemonic skill are robust. Developmental Psychology, 28, 121-125.

10. Baltes, P. B., Lindenberger, U. and Staudinger, U. M. (1995) Die zwei Gesichter der Intelligenz im Alter. Spektrum der Wissenschaft, 10, 52-61.

11. Baltes, P. B. and Mayer, K. U. (eds) (1999) The Berlin Ageing Study: Ageing from 70 to 100 (New York: Cambridge University Press).

12. Baltes, P. B. and Schaie, K. W. (1976) On the plasticity of intelligence in adulthood and old age: where Horn and Donaldson fail. American Psychologist, 31, 720-725.

13. Baltes, P. B. and Staudinger, U. M. (eds) (1996) Interactive Minds: Life-span Perspectives on the Social Foundation of Cognition (New York: Cambridge University Press).

14. Baltes, P. B. and Staudinger, U. M. (2000) Wisdom: a metaheuristic to orchestrate mind and virtue towards excellence. American Psychologist, 55, 122-136.

15. Baltes, P. B., Staudinger, U. M. and Lindenberger, U. (1999) Lifespan psychology: theory and application to intellectual functioning. Annual Review of Psychology, 50, 471-507.

16. Buonomano, D. V. and Merzenich, M. M. (1998) Cortical plasticity: from synapses to maps. In W. M. Cowan, E. M. Shooter, C. F. Stevens and R. F. Thompson (eds) Annual Review of Neuroscience, 21, 149-186.

17. Camp, C. J. (1998) Memory intervention for normal and pathological older adults. Annual Review of Gerontology and Geriatrics, 18, 155-189.

18. Carstensen, L. L., Gross, J. J. and Fung, H. H. (1997) The social context of emotional experience. In K. W. Schaie and M. P. Lawton (eds) Annual Review of Gerontology and Geriatrics (New York, NY: Springer) 17, pp. 325-352.

19. Cattell, R. B. (1971) Abilities: Their Structure, Growth, and Action (Boston, MA: Houghton Mifflin).

20. Changeux, J. P. (1996) Neurotransmitter receptors in the changing brain: allosteric transitions, gene expression and pathology at the molecular level. In D. Magnusson (Ed.) The Life-span Development of Individuals: Behavioural, Neurobiological and Psychosocial Perspectives (Cambridge, UK: Cambridge University Press) pp. 107-138.

21. Charness, N. (1981) Search in chess: Age and skill differences. Journal of Experimental Psychology: Human Perception and Performance, 7, 467-476.

22. Cotman, C. W. (ed) (1985) Synaptic Plasticity (New York: Guilford Press).

23. Craik, F. I. M. and Salthouse, T. A. (eds) (2000) Handbook of Ageing and Cognition (Mahwah, NJ: Erlbaum).

24. Durham, W. H. (1991) Coevolution: Genes, Culture and Human Diversity (Stanford, CA: Stanford University Press).

25. Edelman, G. M. and Tononi, G. (1996) Selection and development: the brain as a complex system. In D. Magnusson (Ed.) The Life-span Development of Individuals: 
Behavioural, Neurobiological and Psychosocial Perspectives (Cambridge, UK: Cambridge University Press), pp. 179-204.

26. Elbert, T., Pantey, C., Wienbruch, C., Rockstroh, B. and Taub, E. (1995) Increased cortical representation of the fingers of the left hand in string players. Science, 270, 305-307.

27. Ericsson, K. A. (1996) The Road to Excellence: The Acquisition of Expert Performance in the Arts and Sciences, Sports and Games (Mahwah, NJ: Erlbaum).

28. Finch, C. E. (1996) Biological bases for plasticity during ageing of individual life histories. In D. Magnusson (ed.) The Life-span Development of Individuals: Behavioural, Neurobiological and Psychosocial Perspectives (Cambridge, UK: Cambridge University Press) pp. 488-511.

29. Finch, C. E. and Sapolsky, R. M. (1999) The evolution of Alzheimer disease, the reproductive schedule, and apoE isoforms. Neurobiology of Ageing, 20, 407-428.

30. Fisher, D. L. (2000) Cognitive ageing and adaptive technologies. In P. C. Stern and L. L. Carstensen (eds) The Ageing Mind (Washington, D.C.: National Academy Press) pp. $166-188$.

31. Freund, A. M. and Baltes, P. B. (2000) The orchestration of selection, optimisation, and compensation: an action-theoretical conceptualization of a theory of developmental regulation. In W. J. Perrig and A. Grob (eds) Control of Human Behaviour, Mental Processes and Consciousness (Mahwah, NJ: Erlbaum) pp. 35-58.

32. Grimm, J. (1860) Rede über das Alter (Berlin: Harrwitz und Grossmann).

33. Hebb, D. O. (1949) The Organization of Behaviour (New York: Wiley).

34. Horn, J. L. (1982) The theory of fluid and crystallized intelligence in relation to concepts of cognitive psychology and ageing in adulthood. In F. I. M. Craik and G. E. Trehub (eds.) Ageing and Cognitive Processes: Advances in the Study of Communication and Affect (New York: Plenum Press) pp. 237-278.

35. Karmiloff-Smith, A. (1992) Beyond Modularity. A Developmental Perspective on Cognitive Science (Cambridge, MA: MIT Press).

36. Kitayama, S. (2000) Cultural variations in cognition: implications for ageing research. In P. C. Stern and L. L. Carstensen (eds) The Ageing Mind (Washington: National Academy Press) pp. 218-237.

37. Kliegl, R. and Baltes, P. B. (1987) Theory-guided analysis of mechanisms of development and ageing mechanisms through testing-the-limits and research on expertise. In C. Schooler and K. W. Schaie (eds) Cognitive Functioning and Social Structure over the Life Course (Norwood, NJ: Ablex) pp. 95-119.

38. Kliegl, R., Smith, J. and Baltes, P. B. (1989) Testing-the-limits and the study of age differences in cognitive plasticity of a mnemonic skill. Developmental Psychology, 25, 247-256.

39. Kliegl, R., Smith, J. and Baltes, P. B. (1990) On the locus and process of magnification of age differences during mnemonic training. Developmental Psychology, 26, 894-904.

40. Klix, F. (1993) Erwachendes Denken: Geistige Leistungen aus evolutionspsychologischer Sicht (Heidelberg: Spektrum Akademischer Verlag).

41. Krampe, R. T. and Ericsson, K. A. (1996) Maintaining excellence: deliberate practice and elite performance in young and older pianists. Journal of Experimental Psychology: General, 125, 331-359.

42. Labouvie-Vief, G. (1997) Cognitive-emotional integration in adulthood. In K. W. Schaie and M. P. Lawton (eds) Annual Review of Gerontology and Geriatrics (New York, NY: Springer) pp. 206-237.

43. Lerner, R. M. (1984) On the Nature of Human Plasticity (New York: Cambridge University Press).

44. Li, K. Z. H., Lindenberger, U., Freund, A. M. and Baltes, P. B. (in press) Walking 
while memorizing: An SOC study of age-related differences in compensatory behaviour under dual-task conditions. Psychological Science.

45. Li, S. C., Lindenberger, U. and Baltes, P. B. (2000) A lifetime from differentiation to dedifferentiation: the fall and rise of covariations between intelligence, information processing and sensory functioning across lifespan. Manuscript in preparation.

46. Lindenberger, U. (2000) Intellektuelle Entwicklung über die Lebensspanne: Überblick und ausgewählte Forschungsbrennpunkte. Psychologische Rundschau, 51, 135-145.

47. Lindenberger, U. and Baltes, P. B. (1999) Die Entwicklungspsychologie der Lebensspanne (Lifespan-Psychologie): Johann Nicolaus Tetens (1736-1807) zu Ehren. Zeitschrift für Psychologie, 207, 299-323.

48. Lindenberger, U. and Baltes, P. B. (1997) Intellectual functioning in old and very old age: cross-sectional results from the Berlin Ageing Study. Psychology and Ageing, 12, 410-432.

49. Lindenberger, U., Marsiske, M. and Baltes, P. B. (2000) Memorizing while walking: increase in dual-task costs from young adulthood to old age. Psychology and Ageing, 15, 417-436.

50. Marsiske, M., Lang, F. R., Baltes, M. M. and Baltes, P. B. (1995) Selective optimisation with compensation: life-span perspectives on successful human development. In R. A. Dixon and L. Bäckman (eds) Compensation for Psychological Defects and Declines: Managing Losses and Promoting Gains (Hillsdale, NJ: Erlbaum) pp. 35-79.

51. Martin, G. M., Austad, S. N. and Johnson, T. E. (1996) Genetic analysis of ageing: role of oxidative damage and environmental stresses. Nature Genetics, 13, 25-34.

52. Park, D. C., Nisbett, R. E. and Hedden, T. (1999) Ageing, culture, and cognition. Journal of Gerontology: Psychological Sciences, 54B, 75-84.

53. Pascual-Leone, A. and Torres, F. (1993) Plasticity of the sensorimotor cortex representation of the reading finger in Braille readers. Brain, 116, 39-52.

54. Pasupathi, M., Staudinger, U. M. and Baltes, P. B. (2001) Seeds of wisdom: Adolescents' knowledge and Judgment about difficult life problems. Developmental Psychology.

55. Recanzone, G. H. (2000) Cerebral cortical plasticity: perception and skill acquisition. In M. S. Gazzaniga (ed) The New Cognitive Neurosciences (Cambridge, MA: The MIT Press) pp. 237-247.

56. Roger, W. A., Fisk, A. D. and Walker, N. (eds) (1996) Ageing and Skilled Performance (Mahwah, NJ: Erlbaum).

57. Rowe, J. W. (1997) Editorial: The new gerontology. Science, 278, 367.

58. Schaie, K. W. (1996) Adult Intellectual Development: The Seattle Longitudinal Study (New York: Cambridge University Press).

59. Simonton, D. K. (1988) Age and outstanding achievement: What do we know after a century of research? Psychological Bulletin, 104, 251-267.

60. Simonton, D. K. (1989) The swan-song phenomenon: last-works effects for 172 classical composers. Psychology and Ageing, 4, 42-47.

61. Singer, T. (2000) Testing-the-Limits in einer mnemonischen Fähigkeit: Eine Studie zur kognitiven Plastizität im hohen Alter. Electronically published Dissertation, Max-Planck-Institute for Human Development, Berlin.

62. Singer, T. and Lindenberger, U. (2000) Plastizität. In H.-W. Wahl and C. Tesch-Römer (eds.) Angewandte Gerontologie in Schlüsselbegriffen, (Stuttgart: Kohlhammer) pp. 39-48.

63. Singer, W. (1995) Development and plasticity of cortical processing architectures. Science, 270, 758-764.

64. Smith, J. and Baltes, P. B. (1999) Life-span perspectives on development. In M. H. 
Bornstein and M. E. Lamb (eds) Developmental Psycholoogy: An Advanced Textbook (Hillsdale, NJ: Erlbaum) pp. 47-72.

65. Squire, L. R. and Kandel, E. R. (1999) Memory: From Mind and Molecules (New York, NY, USA: Scientific American Library/Scientific American Books).

66. Staudinger, U. M. (1999) Older and wiser? Integrating results on the relationship between age and wisdom-related performance. International Journal of Behavioural Development, 23, 641-664.

67. Staudinger, U. M. and Baltes, P. B. (1996) Weisheit als Gegenstand psychologischer Forschung. Psychologische Rundschau, 47, 57-77.

68. Stern, P. C. and Carstensen, L. L. (eds) (2000) The Ageing Mind: Opportunities in Cognitive Research (Washington, D.C.: National Academic Press).

69. Tetens, J. N. (1777) Philosophische Versuche über die menschliche Natur und ihre Entwicklung (Leipzig, Germany: Weidmanns Erben und Reich).

70. Tomasello, M., Kruger, A. C., and Ratner, H. H. (1993) Cultural learning. Behavioural and Brain Sciences, 16, 495-552.

71. Verhaeghen, P., Marcoen, A., Goossens, L. (1992) Improving memory performance in the aged through mnemonic training: a meta-analytic study. Psychology and Ageing, 7, 242-251.

72. Willis, S. L. (1989) Improvement with cognitive training: which dogs learn what tricks? In L. W. Poon, D. C. Rubin and B. A. Wilson (eds) Everyday Cognition in Adulthood and Late Life (Cambridge, UK: Cambridge University Press) pp. 545-569.

\section{About the Authors}

Paul B. Baltes is Director of the Center of Lifespan Psychology at the Max Planck Institute for Human Development and Professor of Psychology at the Free University of Berlin. His research interests, articulated within developmental psychology and gerontology, include the study of intelligence, wisdom, and human ageing. He is also co-editor-in-chief (with Neil Smelser) of the 26-volume International Encyclopedia of the Behavioral and Social Sciences that is scheduled to appear in 2001 (Elsevier)

Tania Singer is a research scientist at the Max Planck Institute for Human Development in Berlin, Germany. Her doctoral thesis was on: Testing-the-Limits in a mnemonic technique: a study of cognitive plasticity in very old age. Her current research interests are in lifespan psychology; cognition and ageing; culture and cognition and longitudinal research in human development. 